\title{
Structural Effects Determining the Reductive Electron Transfer Chemistry of 2.5-Disubstituted Furans - One and "Two-electron" Transfer Behaviour Investigated by Cyclic Voltammetry and UV/VIS/NIR-Spectroelectrochemistry
}

\author{
By Josef Salbeck, Ulrich Schöberl, Knut M. Rapp and Jörg Daub \\ Institut für Organische Chemie der Universität Regensburg, Universitätsstraße 31, \\ W-8400 Regensburg, Federal Republic of Germany
}

(Received January 24, 1991; accepted April 17, 1991)

\section{Radical anions / Dianions / Trianions / One-electron and "Two-electron" transfer processes / Dicyanovinyl substituted heterocycles}

The reductive electron transfer behaviour of 2,5-disubstituted furans with the general formula $\mathbf{A}$ is investigated. A comparison with related dicyanovinyl substituted benzene derivatives, a monosubstituted furan, thiophenes and pyrrols is given. Radical anions, dianions and trianions are characterized by cyclic voltammetry and UV/VIS/NIRspectroelectrochemistry. Electronic spectra are reported. The reduction of $\mathbf{A}$ to their dianions depends sensitively on the length of the $\pi$-conjugated side chains and can be shifted from a stepwise process with two clearly separated waves to an electron transfer mechanism with a single "two-electron" transfer wave in the cyclic voltammogram. The compounds $\mathbf{A}$ with higher conjugated side groups tend to the "merging wave" behaviour. A structural evaluation of these findings is discussed. The furans $\mathbf{A}$ and the thiophenes exhibit electrochemichromic behaviour. Applications of $\mathbf{A}$ in material science chemistry are shortly adressed.

Das Elektronentransferverhalten von 2,5 disubstituierten Furanen der allgemeinen Formel A wird untersucht. Ein Vergleich mit strukturell vergleichbaren benzoiden Verbindungen, monosubstituiertem Furan, Thiophenen und Pyrrolderivaten wird durchgeführt. Radikalanionen, Dianionen und in einzelnen Fällen auch Trianionen werden durch Cyclovoltametrie und teilweise auch UV/VIS/NIR-Spektroelektrochemie nachgewiesen und charakterisiert. Der Ablauf der reduktiven Elektronenübertragung für die Umwandlung von $\mathbf{A}$ in die entsprechenden Dianionen zeigt im cyclischen Voltamogramm strukturabhängiges Verhalten, das von einem Zweistufenprozeß bis zur einstufigen Zwei-Elektronenübertragung reicht. Der Zusammenhang zwischen diesem Elektronentransferverhalten und der Substratstruktur wird diskutiert. Verbindungen A mit höher konjugierten 
Seitenketten neigen zu einem Einstufenprozeß bei der Bildung des Dianions. Die zweifachsubstituierten Furane A und Thiophene sind elektrochemichrom. Auf Anwendungen der Verbindungen wird kurz eingegangen.

\section{Introduction}

The importance of reversible electron-transfer materials is far reaching and contributing to fields so different as chemical reactions in homogeneous solution [2] and material science chemistry of solids [3]. Therefore, to design tailor-made molecular units and to uncover structure/property-relationships is a continuous challenge. Some of the topics which have to be considered along these investigations are: (a) dependency of the redox potentials on the structure, (b) reversibility of the electron-transfer processes, (c) fatique resistance of the electron-transfer active units, (d) stability and structure of the intermediates, and (e) mechanism of multistep electrontransfer either in consecutive one-electron transfer or "two-electron"-transfer steps. The results of these studies may have impacts towards various sections of chemistry, as for example electron transfer catalysis [4], polargroup transfer vs SET (single electron transfer)-type mechanism [5], electrochromism [6], design of new conducting charge-transfer salts [7], organic photoconductive materials [8], or even the evaluation of new magnetic materials [9].

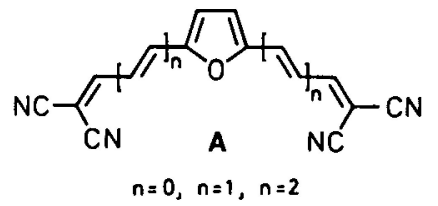

This study is dealing with substituted furans of the general formula $\mathbf{A}$ and related compounds like substituted benzenes, thiophenes, and pyrrols. The structure-dependent reductive electron transfer of these compounds is investigated, using cyclic voltammetry and spectroelectrochemistry as analytical tools $[10,11]$. The work is part of a programme to outline the potential of low-molecular-weight carbohydrates as source-chemicals for optoelectronic materials. Hence, the furans of this study were synthesized from sucrose [12] by efficient synthetic multistep procedures [13, 14].

\section{Experimental section}

\subsection{Electrochemical and spectroelectrochemical experiments}

All measurements were undertaken at room temperature in purified acetonitrile [15] using $0.1 \mathrm{~m}$ tetrabutylammonium hexafluorophosphate (TBAHFP) as supporting electrolyte. 
Table 1. Characteristic (most intensive) VIS-absorption maxima ${ }^{a}$ of the neutral compounds, radical anions and dianions of 5, 6 and 7 (see Scheme 1).

\begin{tabular}{llll}
\hline & Neutral compounds & Radical anion & Dianion \\
\hline $\mathbf{5 a}$ & $392(4.53) 409(\mathrm{~s})$ & $597(5.10)$ & $493(4.47)$ \\
$\mathbf{5 b}$ & $423(4.58)$ & $663(5.20)$ & $603(4.76)$ \\
$\mathbf{5 c}$ & $420(4.57)$ & $604(5.00)$ & $515(4.76)$ \\
$\mathbf{6 a}$ & $395(4.58) 415(4.48)$ & $588(4.98)$ & $460(4.63)$ \\
$\mathbf{6 b}$ & $423(4.60)$ & $655(5.16)$ & $570(4.80)$ \\
$\mathbf{6 c}$ & $417(4.58)$ & $601(4.94)$ & $529(4.58)$ \\
$\mathbf{7 a}$ & $435(4.56)$ & $690(4.81)$ & $545(4.42)$ \\
$\mathbf{7 b}$ & $461(4.61)$ & $770(4.85)$ & $540(4.64)$ \\
$\mathbf{7 c}$ & $480(4.63)$ & $793(5.04)$ & $585(4.69)$ \\
$\mathbf{7 d}$ & $514(4.63)$ & 930 & $617(4.86)$ \\
$\mathbf{7 e}$ & $430(4.51)$ & 596 & 545 \\
$\mathbf{7 f}$ & $461(4.66)$ & $720(5.10)$ & $593(5.0)$ \\
$\mathbf{7 g}$ & $486(4.65)$ & $821(5.05)$ & $601(4.76)$ \\
\hline
\end{tabular}

a $\lambda_{\max }$ in $\mathrm{nm}, \log \varepsilon$ in parentheses, $(\mathrm{s})=$ shoulder.

Cyclic voltammetry: Function generator Amel 568, potentiostat Amel 553, online registration via multichannel analog/digital converter ANA86/3 (Computer Centre, University of Regensburg). One-compartment cell containing a platinum-disc $(r=1.5 \mathrm{~mm})$ working electrode, a platinum auxiliary electrode and a $\mathrm{Ag} / \mathrm{AgCl}$ quasi-reference electrode. Potentials are refered to ferrocene (FOC) as internal standard.

To compensate the different time scales in conventional cyclic voltammetry and spectroelectrochemistry, thin-layer voltammetry was employed. With the exception of $7 e$ (see Scheme 1) all 2.5-disubstituted furans and thiophenes in this study showed reversible formation of the radical anions and dianions.

Thin-layer voltammetry: Equipment as described above, modified by a mobile mounted half ball $(r=3 \mathrm{~mm})$ [16] and moveable platinum-disk $(r=1.5 \mathrm{~mm})$ working electrode (thickness $20 \pm 5 \mu \mathrm{m}$ ).

Spectroelectrochemistry: Potentiostat Amel 550, thin-layer cell $(150 \mu \mathrm{m})$ with optically-transparent ITO-electrodes (as described in [17]). The electronic spectra were obtained by a Perkin Elmer Lambda 9 spectrophotometer (spectral range from 320 to $2500 \mathrm{~nm}$ ) and by a Shimadzu $210 \mathrm{UV} /$ VIS spectrophotometer (spectral range 320 to 800). Computerized online registration was applied. Spectroscopic data are given in Table 1.

To determine the redox potentials of overlapping waves, the tabulated values of Myers/Shain [18] and Richardson/Taube [19] were put together, and by cubic spline interpolation a working curve was obtained which allows to determine $\Delta E^{\mathrm{o}}=E_{\mathrm{l}}^{\mathrm{o}}-E_{\mathrm{II}}^{\mathrm{o}}$ in the range from $200 \mathrm{mV}$ to $-180 \mathrm{mV}$ by the half-width $E_{\mathrm{p}}-E_{\mathrm{p} / 2}$ of the signal.

\subsection{Compounds employed}

The compounds involved in this study are given in Scheme 1.

Synthetic procedures: Benzenoid compounds 1a, 2a and 3a, see: Lit. [20]. Compounds 1b, 2b and 3b, see: Lit. [21]. Furanoid compounds 7b, d, e, f, g, see: K. M. Rapp, unpublished. Synthesis of the heteroaromatic compounds $4,5,6,7 a, c, 8,9$, see: U. Schöberl, Thesis University of Regensburg, in preparation. 

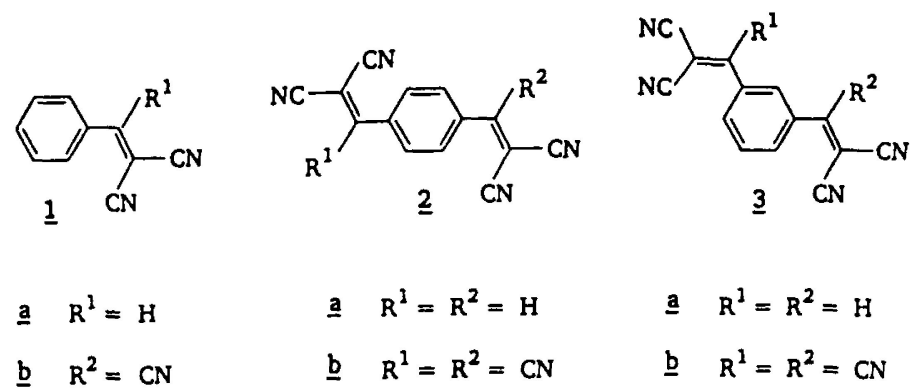

a $\quad \mathrm{R}^{1}=\mathrm{R}^{2}=\mathrm{H}$

b $\quad \mathrm{R}^{1}=\mathrm{R}^{2}=\mathrm{CN}$

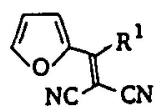

4

a $\quad R^{1}=H$

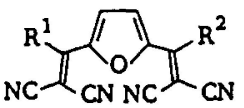

5

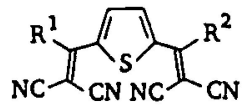

6
a $R^{1}=R^{2}=H$
a $\quad \mathrm{R}^{1}=\mathrm{R}^{2}=\mathrm{H}$
b $\quad R^{1}=R^{2}=C N$
b $R^{1}=R^{2}=C N$
c $\mathrm{R}^{1}=\mathrm{H}, \mathrm{R}^{2}=\mathrm{CN}$
c $\mathrm{R}^{1}=\mathrm{H}, \mathrm{R}^{2}=\mathrm{CN}$

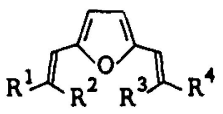

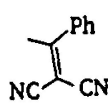

CP

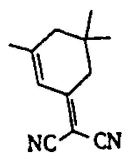

IP

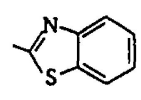

BT

$$
\begin{aligned}
& \text { a } \quad \mathrm{R}^{1}=\mathrm{CN}, \mathrm{R}^{2}=\mathrm{CN}, \mathrm{R}^{3}=\mathrm{H}, \quad \mathrm{R}^{4}=\mathrm{CP} \text {, } \\
& \text { b } R^{1}=C N, \quad R^{2}=C N, \quad R^{3}=H, \quad R^{4}=I P \text {, } \\
& \text { c } R^{1}=C P, \quad R^{2}=H, \quad R^{3}=H, \quad R^{4}=C P \text {, } \\
& \text { d } R^{1}=\mathrm{IP}, \quad \mathrm{R}^{2}=\mathrm{H}, \quad \mathrm{R}^{3}=\mathrm{H}, \quad \mathrm{R}^{4}=\mathrm{IP} \text {, } \\
& \text { e } R^{1}=C N, R^{2}=C N, R^{3}=C N, R^{4}=B T \text {, } \\
& \text { f } R^{1}=B T, \quad R^{2}=C N, \quad R^{3}=C N, R^{4}=B T \text {, } \\
& \text { g } R^{1}=I P, \quad R^{2}=H, \quad R^{3}=C N, \quad R^{4}=B T \text {, }
\end{aligned}
$$

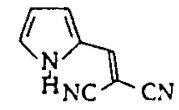

$\underline{8}$

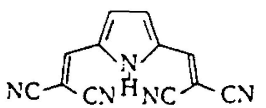

g

Scheme 1. Dicyanovinyl substituted arenes and heteroarenes. 
Table 2. Standard reduction potentials $E^{\circ}$ (in $\mathrm{mV}$ vs. FOC as otherwise indicated) obtained by cyclic voltammetry ${ }^{a}$ ).

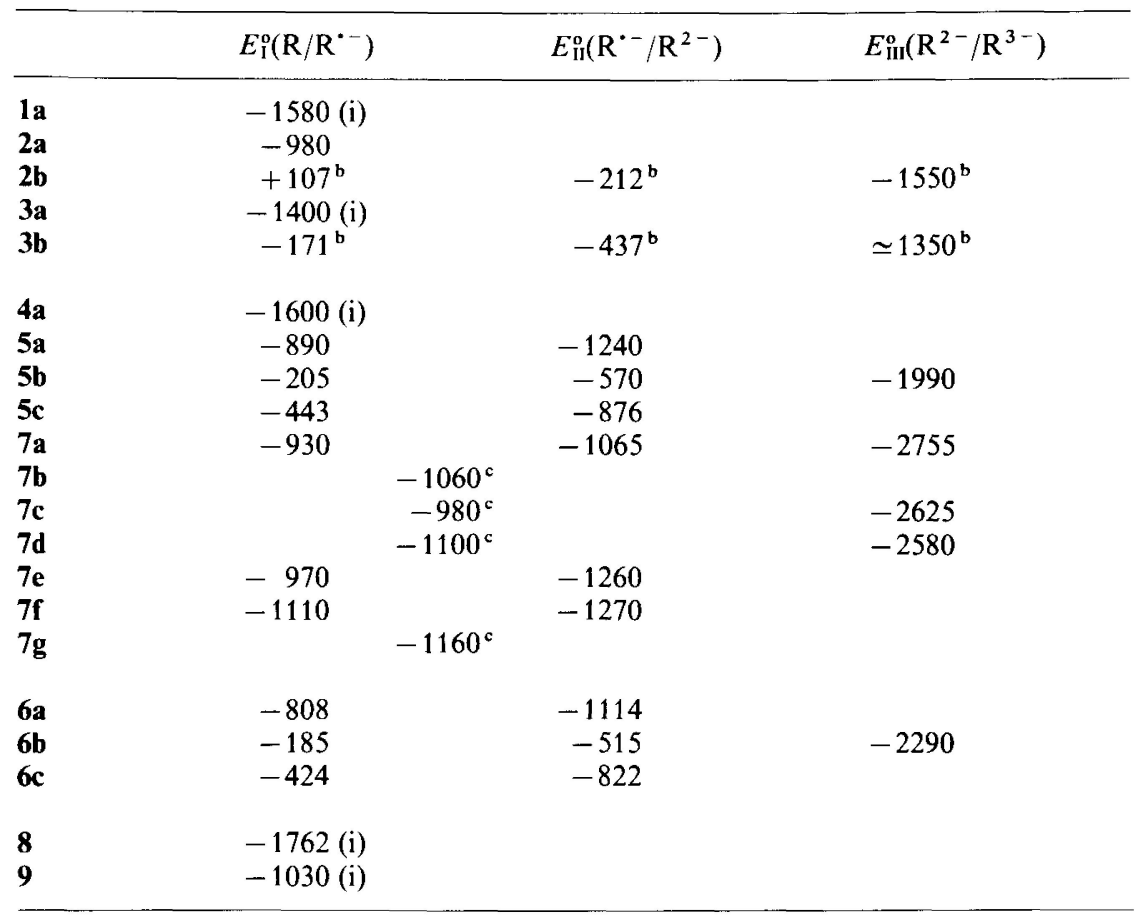

(i) indicates the peak potential of an irreversible process (EC-behaviour).

${ }^{a}$ In acetonitrile, $0.1 \mathrm{~m}$ TBAHFP, scan $25-500 \mathrm{mV} / \mathrm{s}$.

${ }^{b}$ In dichlormethane, reference electrode $\mathrm{Ag} / \mathrm{AgCl}$ [21].

c "Two-electron transfer" wave, $E^{o}$ correspond to $\left(E_{\mathrm{I}}^{o}+E_{\mathrm{II}}^{\circ}\right) / 2$.

\section{Results}

\subsection{Cyclic voltammetry}

Table 2 summarizes the reduction potentials obtained by cyclic voltammetry. To facilitate discussion Table 2 is broken into four sections with section one comprising the benzene derivatives $1-3$, section two the furans 4,5 , and 7 , section three the thiophenes 6 , and section four the pyrrol derivatives 8 and 9 . If experimentally accessible the half-wave potentials for the formation of the trianions were included.

Phenomenologically, the cyclic voltammograms of those samples exhibiting reversible electron-transfer behaviour may be divided into two sections: Section one (compounds $2 \mathbf{b}, 3 \mathbf{b}, 5 \mathbf{a}-\mathbf{c}, \mathbf{6 a}-\mathbf{c}, 7 \mathbf{7}, 7 \mathbf{7 e}, 7 \mathbf{7}$ ) containing those compounds with two clearly resolved redox steps and a positive 

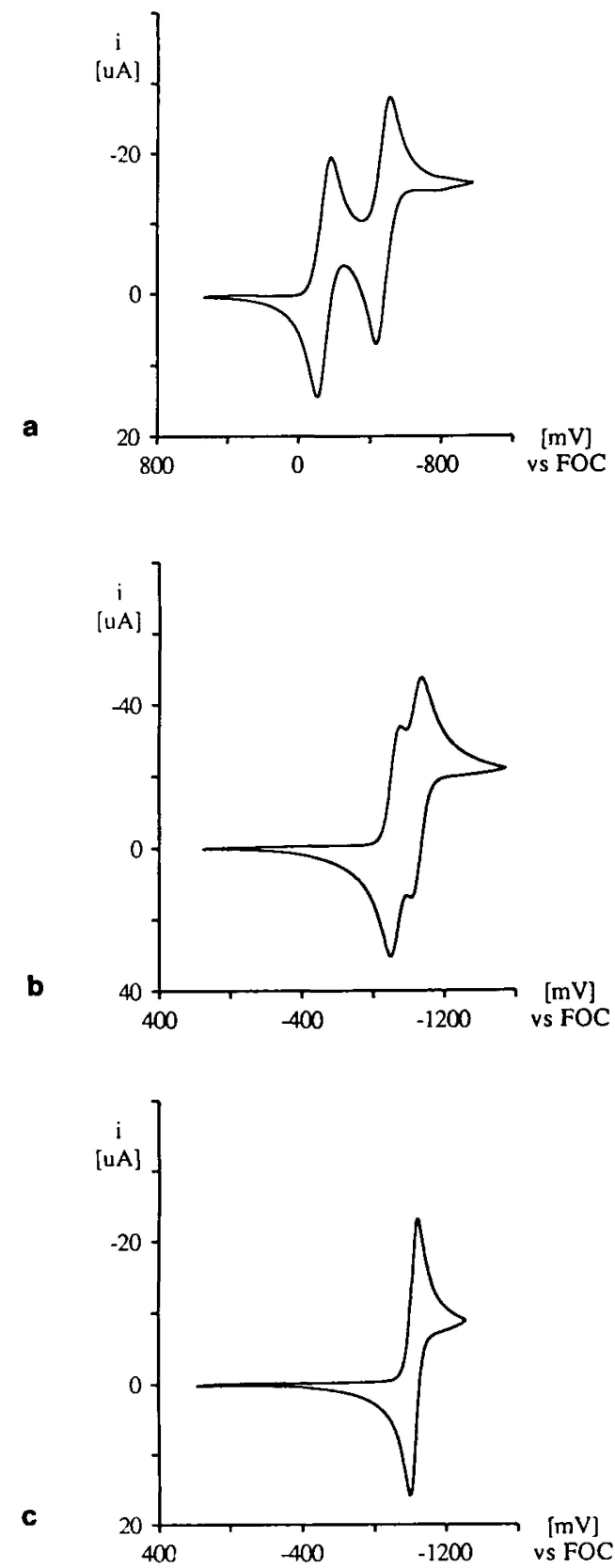

Fig. 1. Cyclovoltammogram of $6 \mathbf{b}, 7 \mathbf{a}$ and $7 \mathrm{c}$ in acetonitrile/TBAHFP, $0.1 \mathrm{~m}, c=$ $1.1 \times 10^{-3} \mathrm{~m}$ (6b) (top); $1.8 \times 10^{-3} \mathrm{~m}$ (7a) (middle); $0.8 \times 10^{-3} \mathrm{~m}$ (7c) (bottom); scan $50 \mathrm{mV} / \mathrm{s}$, Pt-electrode. 


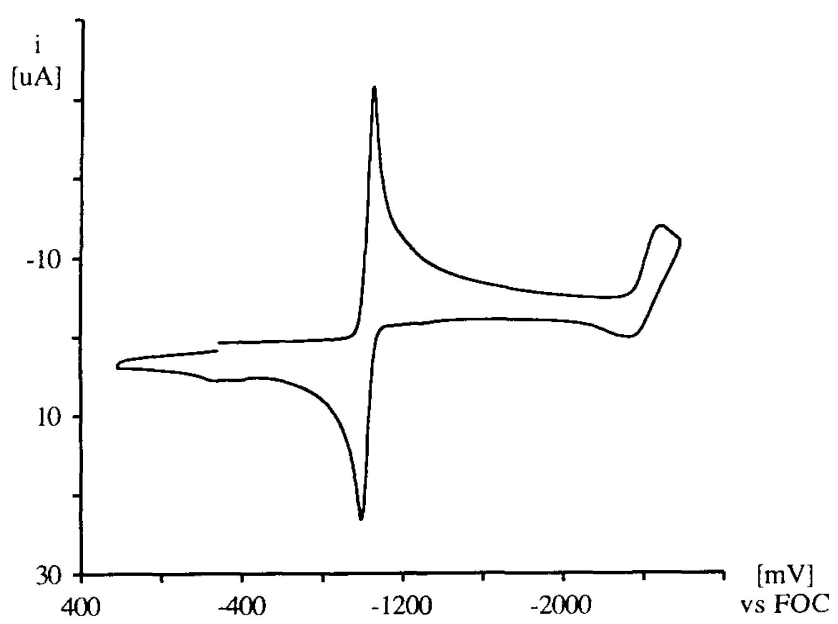

Fig. 2. Cyclovoltammogram of $\mathbf{7 d}$ in acetonitrile/TBAHFP $0.1 \mathrm{~m}$, including radical trianion formation, $c=0.7 \times 10^{-3} \mathrm{~m}$, scan $250 \mathrm{mV} / \mathrm{s}$, Pt-electrode.

difference of first and second reduction wave, and section two (compounds $7 \mathbf{b}-\mathbf{d}, 7 \mathbf{g}$ ) comprising the compounds showing a single $2 \mathrm{e}^{-}$-wave with a potential difference of less than $0 \mathrm{mV}$. A discussion of these results will be given afterwards.

For illustration, representative cyclic voltammograms of thiophene $\mathbf{6 b}$, furan $7 \mathbf{a}$ and furan $7 \mathbf{c}$ are given in Fig. 1. Radical anion and dianion formations in $\mathbf{6 b}$ (Fig. 1 a) constitute two well-defined one-electron transfer waves. The two half waves in $7 \mathbf{a}$ (Fig. $1 \mathrm{~b}$ ) are in a process of merging while 7c (Fig. 1c) exhibits a clear "two-electron" wave. The formation of the radical trianion of $\mathbf{7 d}$ is shown in Fig. 2. Thiazole derivatives $7 \mathbf{e}, \mathbf{7 f}$, and $\mathbf{7 g}$ contrast in their electron transfer behaviour. Whereas $7 \mathbf{f}$ (two one-electron transfer waves) and $\mathbf{7 g}$ (one two-electron wave) are reversibly reduced to their dianions the cyclic voltammogram of $7 \mathbf{e}$ shows a complex feature which best is documented by the multisweep thin-layer-voltammogram (Fig. 3). The appearance of the new peaks can be either rationalized by an EC-type mechanism, containing a fast chemical step subsequent to the oneelectron reduction, or by the deposition of a film on the electrode surface. The process is partially reversible. More detailed investigations on the electron transfer chemistry of $\mathbf{7 e}$ are in progress.

The single waves observed at the reduction of $7 \mathbf{b}-\mathbf{d}$, and $7 \mathrm{~g}$ correspond to superposed signals representing averaged potentials. The two standard reduction potentials $E_{\mathrm{I}}^{\mathrm{o}}$ and $E_{\mathrm{II}}^{\mathrm{o}}$ were evaluated by a line-shape analysis as described by Myers and Shain [18]. Since that as well as other methods 


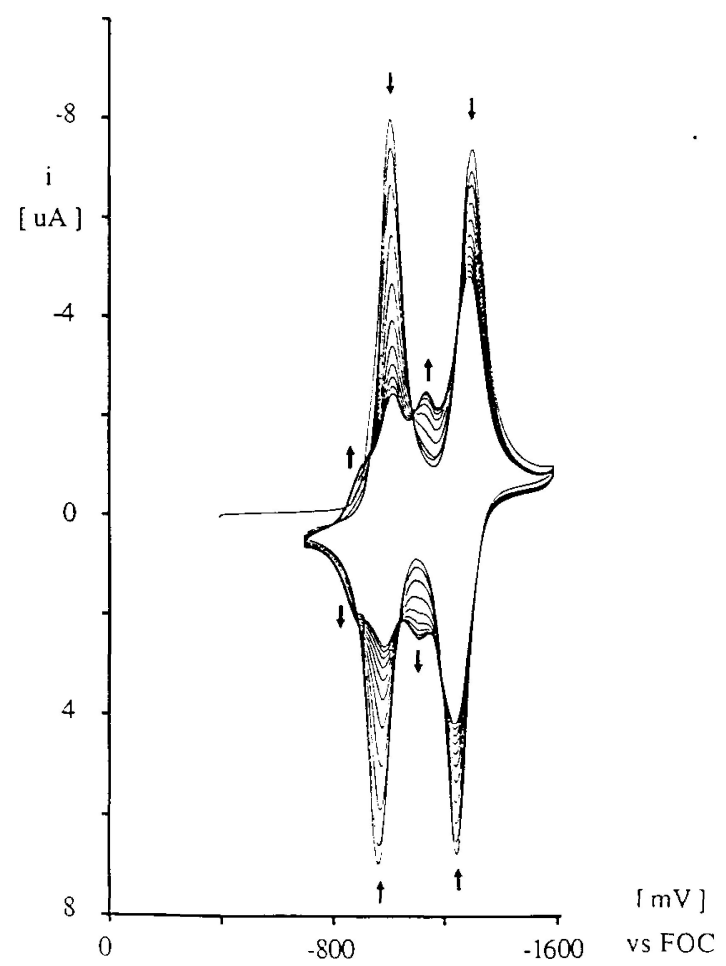

Fig. 3. Multisweep thin-layer voltammogram of $7 \mathbf{e}$ in acetonitrile/TBAHFP, $0.1 \mathrm{~m}, c=$ $1.3 \times 10^{-3} \mathrm{~m}$, scan $50 \mathrm{mV} / \mathrm{s}$, Pt-electrode.

severely rely on certain basic approximations [22] and since for potentials differences $\Delta E^{\circ}<-180 \mathrm{mV}$ the experimental parameters $E_{\mathrm{p} / 2}-E_{\mathrm{p}}$ approach a limiting value we included spectroelectrochemistry to determine the potential differences (vide infra).

\subsection{Spectroelectrochemistry}

The spectra of the radical anions and dianions of 5, 6 and 7 generated electrochemically were recorded. Whereas cyclovoltammetry of $\mathbf{7 b - d}$ and $7 \mathrm{~g}$ provides unresolved signals for the radical anion and dianion formation the spectra of these intermediates could clearly be obtained by spectroelectrochemistry. The equilibrium constants of the disproportionation equilibria of the radical anions could therefore be determined, and this in turn allowed to calculate the potential differences of the two reduction 
Table 3. Half-peak width $E_{\mathrm{p}}-E_{\mathrm{p} / 2}$ and standard potential differences $\Delta E^{\circ}$ of the compounds $7 \mathbf{b}-\mathbf{d}$ and $7 \mathrm{~g}$ and theoretical values for two non-interacting redox groups.

\begin{tabular}{llllll}
\hline $\begin{array}{l}K_{\mathrm{eq}} \\
\text { spectroel. }\end{array}$ & $\begin{array}{l}\Delta E^{\mathrm{ob}} \\
\text { spectroel. } \\
{[\mathrm{mV}]}\end{array}$ & $\begin{array}{l}E_{\mathrm{p}}-E_{\mathrm{p} / 2} \\
\text { theoret. } \\
{[\mathrm{mV}]}\end{array}$ & $\begin{array}{l}E_{\mathrm{p}}-E_{\mathrm{p} / 2} \mathrm{c} \\
\mathrm{CV} \\
{[\mathrm{mV}]}\end{array}$ & $\begin{array}{l}\Delta E^{\mathrm{od}} \\
\mathrm{CV} \\
{[\mathrm{mV}]}\end{array}$ \\
\hline $\mathbf{7 b}$ & $0.40^{\mathrm{a}}$ & -23 & 36.5 & 37 & -21 \\
$7 \mathbf{c}$ & $0.30^{\mathrm{a}}$ & -30 & 35 & 39 & -10 \\
$7 \mathrm{~g}$ & $0.12^{\mathrm{a}}$ & -53 & 33.5 & 37 & -21 \\
$7 \mathbf{d}$ & $\sim 1.6 \times 10^{-5 \mathrm{a}}$ & -280 & 29 & 29 & $<-180$ \\
& $4^{\mathbf{e}}$ & +35.6 & 57 & $\begin{array}{l}\text { non-interacting } \\
\text { same potential }\end{array}$ & \\
\hline
\end{tabular}

a Calculated from spectroelectrochemical measurements.

${ }^{b}$ Calculated by Eq. 1 .

c Measured by cyclic voltammetry.

d Calculated from cyclic voltammetry.

- Theoretical values for comparison.

processes $\left(\Delta E^{\circ}=E_{\mathrm{I}}^{\mathrm{o}}-E_{\mathrm{II}}^{\mathrm{o}}\right)$ without taking recourse to further assumptions (see Eq. 1) [23]:

$$
\begin{aligned}
& A \stackrel{E_{1}^{0}}{\rightleftharpoons} A^{\cdot-} \stackrel{E_{\mathrm{II}}^{0}}{\rightleftharpoons} A^{2-} \\
& A^{2-}+A \stackrel{K_{\text {eq }}}{\rightleftharpoons} 2 A^{\cdot-} \\
& K_{\mathrm{eq}}=\frac{\left[\mathrm{A}^{-}\right]^{2}}{[A]\left[A^{2-}\right]}=\exp \left[\frac{n F}{R T} \Delta E^{0}\right] \\
& \Delta E^{0}=E_{\mathrm{l}}^{0}-E_{\mathrm{II}}^{0} .
\end{aligned}
$$

The results are given in Table 3 .

The inverse order of the two redox potentials (Table 3) needs short commentation. At first, a positive (stabilizing) interaction between both redox subunits must exist. Due to the estimate that two non-interacting groups may at best approach a limiting potential difference $\Delta E^{\circ}$ of $35.6 \mathrm{mV}$, the half-peak width $\left(E_{\mathrm{p}}-E_{\mathrm{p} / 2}\right)$ derived therefrom would lead to $57 \mathrm{mV}$ which is significantly larger than the experimentally determined values (Table 3). If a theoretical potential difference $\Delta E^{\circ}$ of $0 \mathrm{mV}$ is assumed again a too large half-peak potential difference $\left(E_{\mathrm{p}}-E_{\mathrm{p} / 2}\right)$ of $42 \mathrm{mV}$ results.

To portray spectroelectrochemistry, representative diagrams are given. In each of the Figs. 4 to 8 the cyclic voltammogram of the compound is shown in the inset using an arrow to indicate the potential-range for generating the new species. Figure 4 shows the formation of the radical anion (upper half) and the dianion (lower half) of thiophene $\mathbf{6 b}$. Radical 

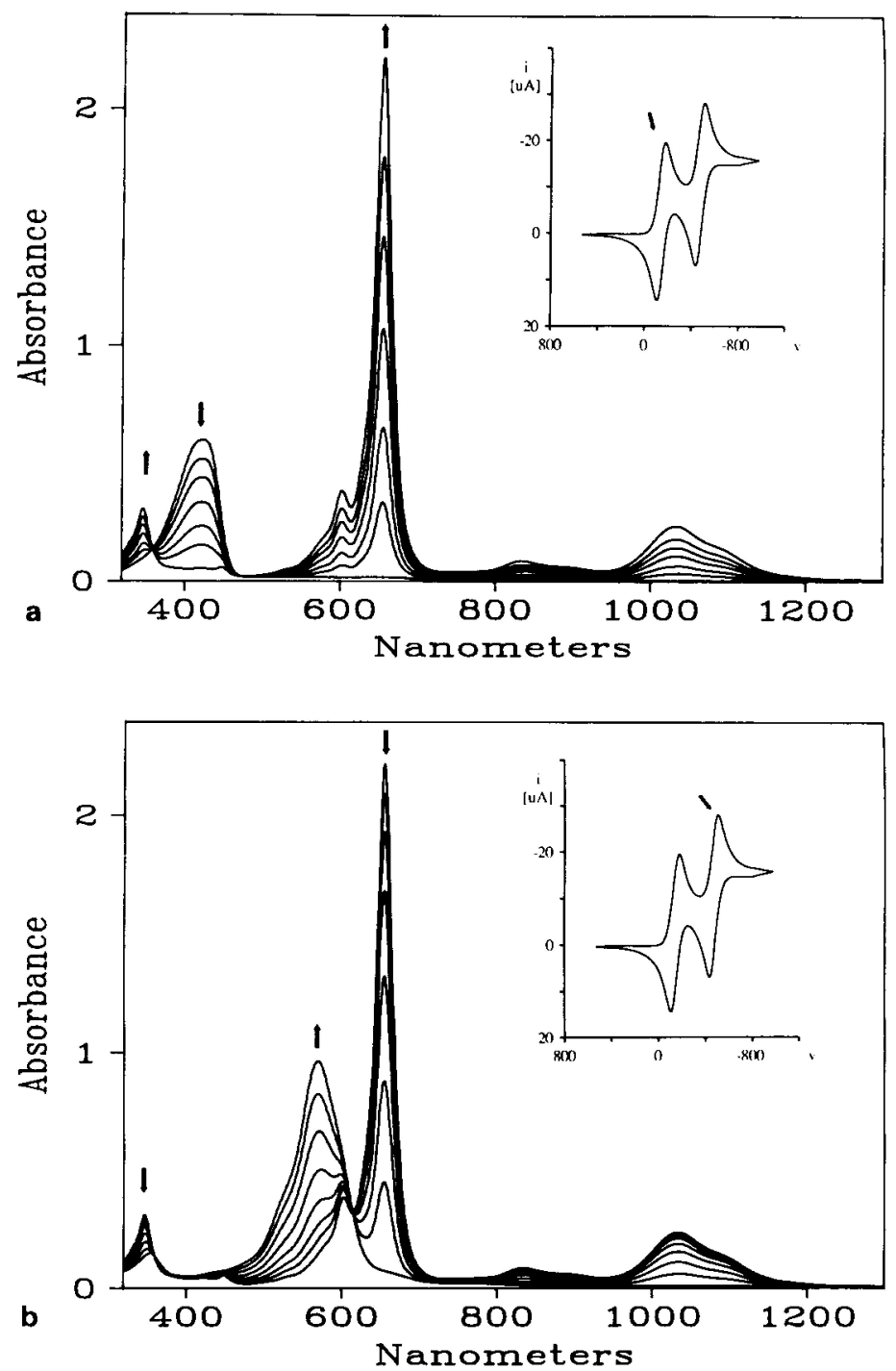

Fig. 4. Spectroelectrogram of $6 \mathrm{~b}$ in acetonitrile/TBAHFP $0.1 \mathrm{~m}, c=1.1 \times 10^{-3} \mathrm{~m}$, inset: $\mathrm{CV}$ under same conditions; top: Formation of the radical anion; bottom: Formation of the dianion.

anion $6 \mathrm{~b}^{\cdot-}$ has a sharp peak at $655 \mathrm{~nm}$ whereas dianion formation is indicated by the appearance of a strong peak at $570 \mathrm{~nm}$. By example of furan 7a (Fig. 5) the spectra for a case of less resolved cyclovoltammetric waves are given. Notably, either radical anion formation (Fig. 5, top) as 

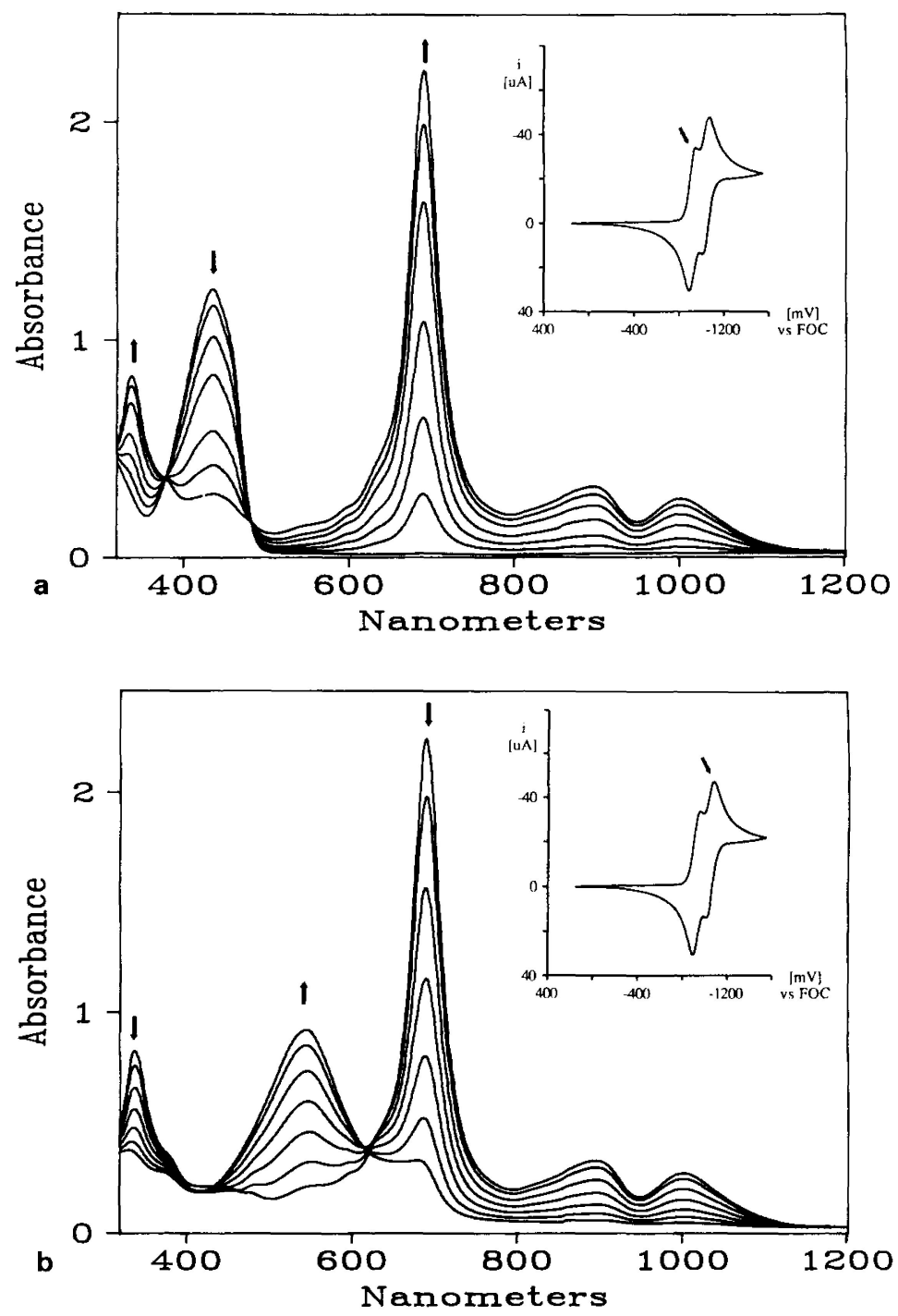

Fig. 5. Spectroelectrogram of $7 \mathrm{a}$ in acetonitrile/TBAHFP $0.1 \mathrm{~m}, c=2.2 \times 10^{-3} \mathrm{~m}$, inset: $\mathrm{CV}$ under same conditions; top: Formation of the radical anion; bottom: Formation of the dianion.

well as dianion formation (Fig. 5, bottom) can clearly be monitored. In Fig. 6 the spectra corresponding to the "two-electron" wave reduction process of furan $\mathbf{7 b}$ are accumulated, demonstrating that the experimental time scale of spectroelectrochemistry allows to identify the radical anion 

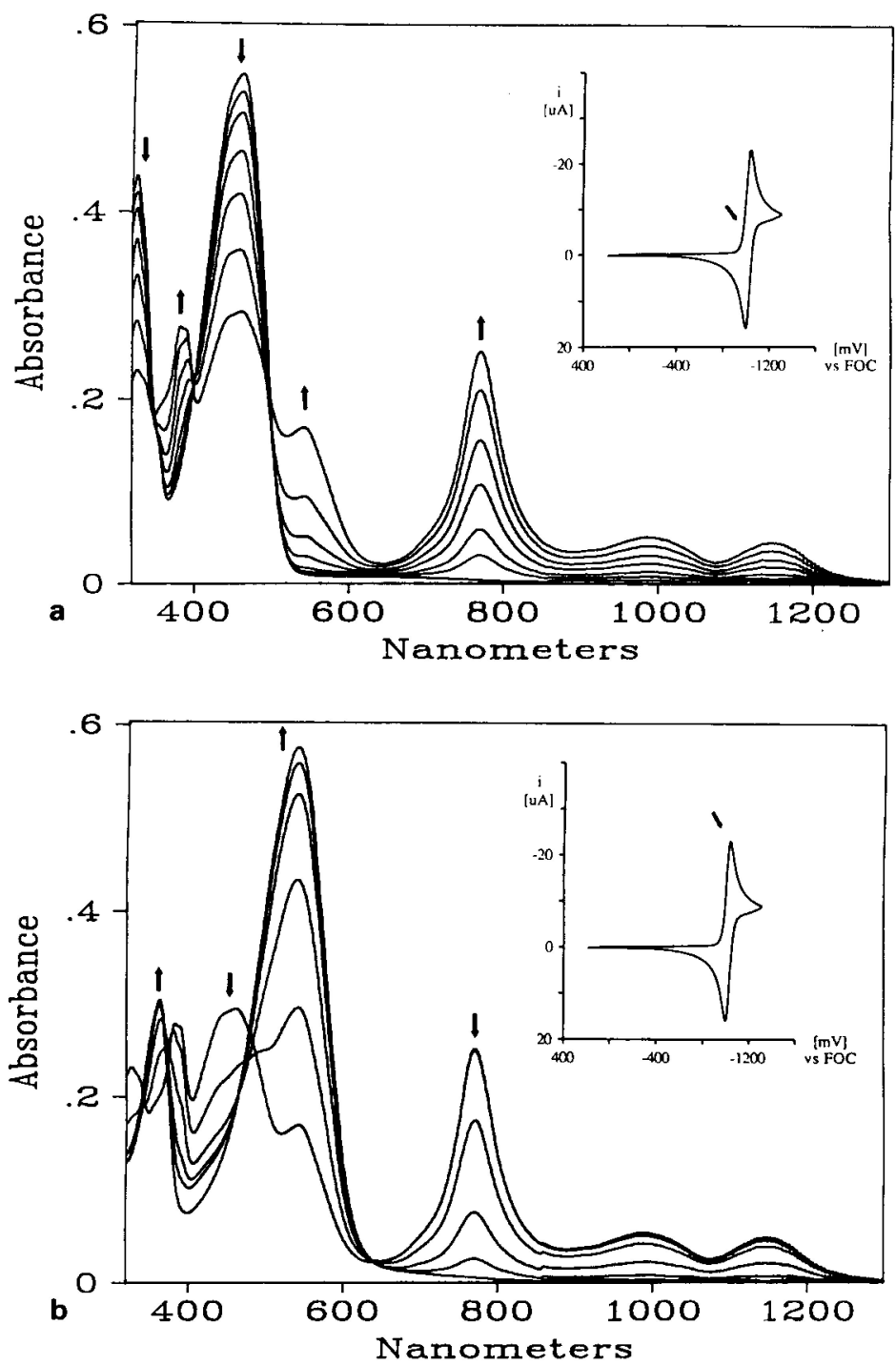

Fig. 6. Spectroelectrogram of $7 \mathrm{~b}$ in acetonitrile/TBAHFP $0.1 \mathrm{~m}, c=1 \times 10^{-3} \mathrm{~m}$, inset: $\mathrm{CV}$ under same conditions; top: Formation of the radical anion, in equilibrium with the dianion; bottom: Further reduction to the dianion.

spectroscopically. If the potential is kept at the onset of the wave (Fig. 6, top) a signal at $770 \mathrm{~nm}$ appears which has to be assigned to the radical anion $\mathbf{7 b}^{\circ-}$. Sweeping towards more negative potential leads to the appearance of a signal at $540 \mathrm{~nm}$ representing the formation of the dianion. Spectroelectrochemistry of $7 \mathrm{c}$ provides almost the same findings. 


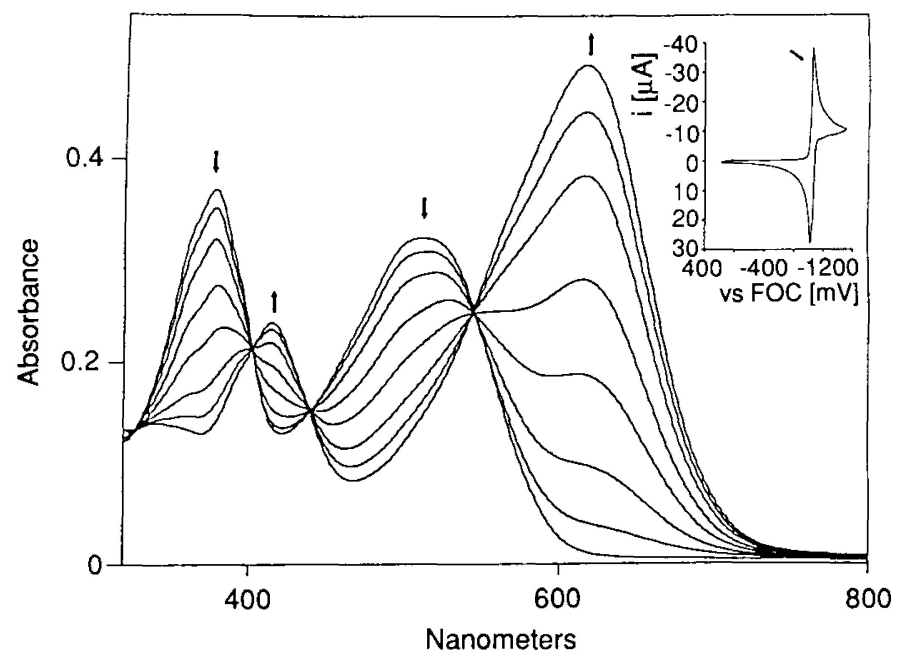

Fig. 7. Spectroelectrogram of $\mathbf{7 d}$ in acetonitrile/TBAHFP $0.1 \mathrm{~m}$, ultimate conversion of the neutral compound into the dianion, $c=0.7 \times 10^{-3} \mathrm{~m}$, inset: $\mathrm{CV}$ under same conditions.

On reduction, there is a subtle difference between bishexatrienyl derivative 7d (Fig. 7) and the aforementioned compounds $\mathbf{7 b}$ and $\mathbf{7 c}$. Four isosbestic points establish the ultimate conversion of the neutral compound 7d into a species with a signal at $617 \mathrm{~nm}$, which has to be assigned to the dianion $7 \mathbf{d}^{2-}$. However, a careful inspection of the long-wave-length part of the spectrum uncovers a weak absorption at $930 \mathrm{~nm}$ which is likely to be due to the radical anion. The evaluation of the equilibrium of disproportionation, assuming $\lg \varepsilon=5$ for the absorption band of the radical anion, yields a potential difference of $-280 \mathrm{mV}$. This suggests increased stabilization of the dianion compared to the radical anion.

As already mentioned before polyene $7 \mathbf{e}$ shows an electron-transfer behaviour not completely understood yet. Nevertheless, the spectra of the radical anion $7 \mathrm{e}^{--}$and the dianion $7 \mathrm{e}^{2-}$ could undoubtedly be established (Table 1). Spectroelectrochemistry of $7 \mathrm{~g}$ gives approximately the same feature as shown by 7c: Despite the fact that cyclic voltammetry gives a "twoelectron" wave the radical anion can be identified by a absorption band at $821 \mathrm{~nm}$.

The final example dealing with bisvinyl compound $7 \mathbf{f}$ delivers less resolved waves in the cyclic voltammogram. Again by spectroelectrochemistry sharp absorptions assigned to the radical anion and the dianion are obtained as shown by the two- (Fig. 8) and three-dimensional (Fig. 9) representations. 

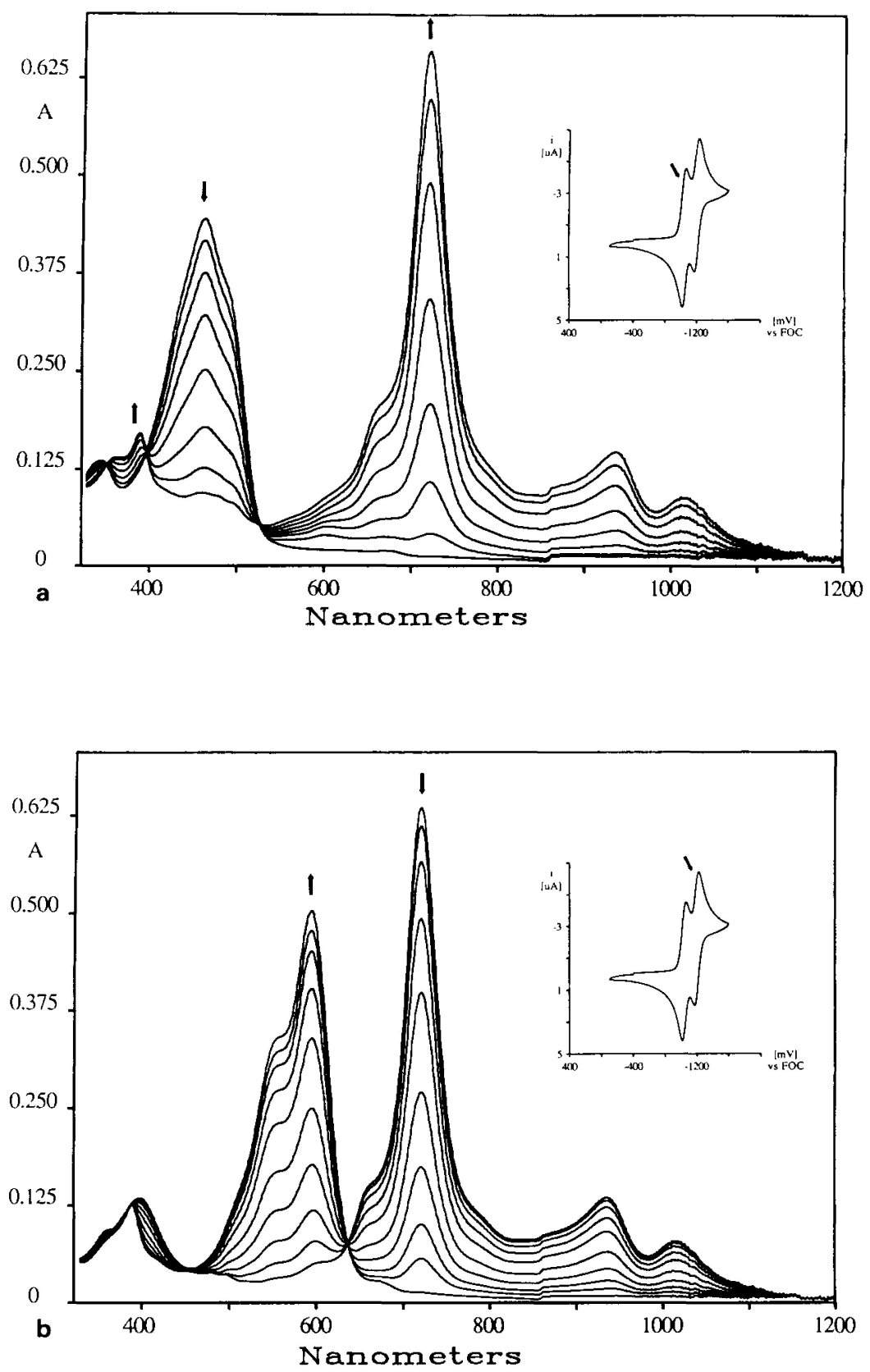

Fig. 8. Spectroelectrogram of $7 \mathrm{f}$ in acetonitrile/TBAHFP $0.1 \mathrm{~m}, c=0.7 \times 10^{-3} \mathrm{~m}$, inset: $\mathrm{CV}$ under same conditions; top: Formation of the radical anion; bottom: Formation of the dianion. 


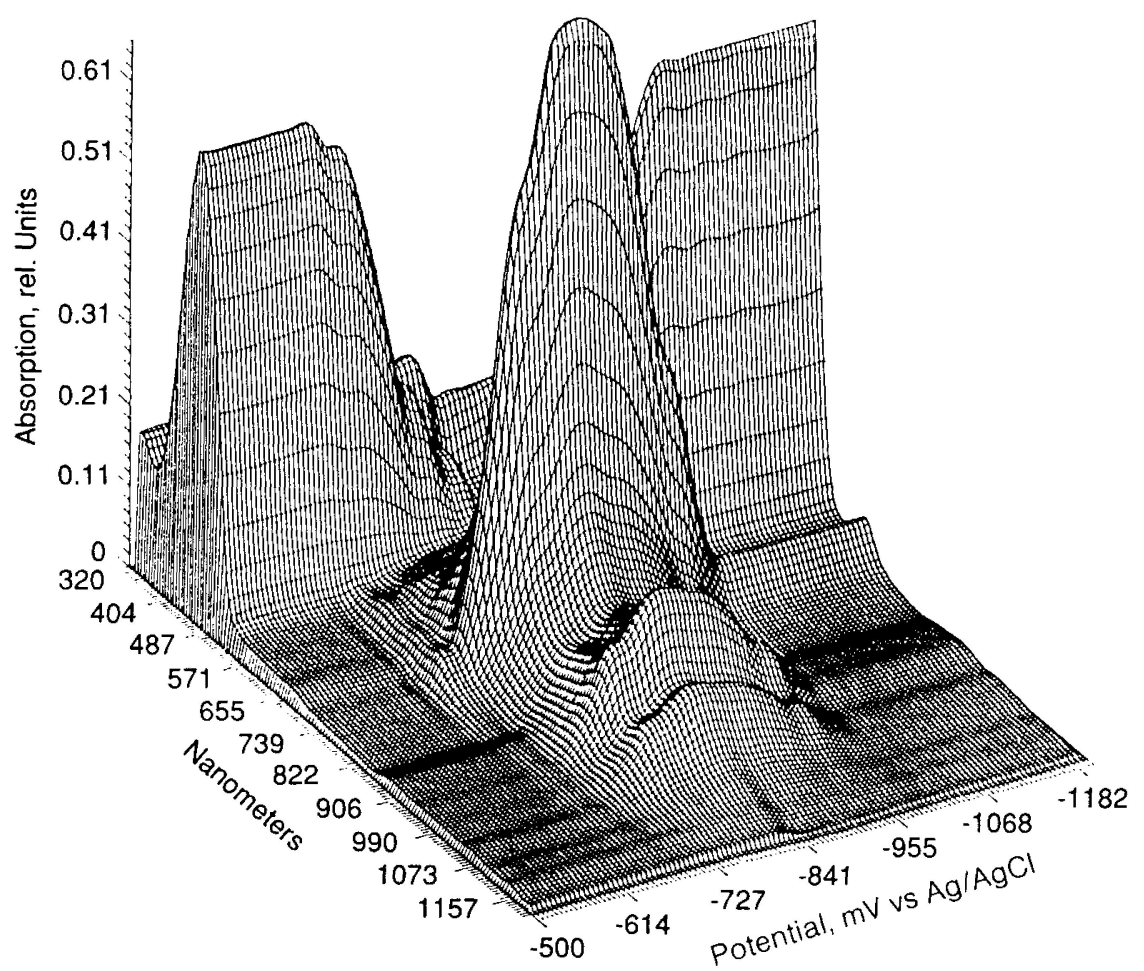

Fig. 9. Three-dimensional representation of the spectroelectrogram during the reduction of $7 \mathbf{f}$ to the radical anion and further to the dianion.

\section{Discussion}

These investigations demonstrate three important findings: In the first place the aromatic core in the dicyanovinyl substituted arenes and heteroarenes significantly determines the chemical stability of the radical anions and dianions (reversibility or irreversibility of the electron transfer behaviour) secondly, the length of the unsaturated side chain controls whether the dianion formation occurs in two consecutive one-electron transfer steps or in a two-electron wave, concealing two coupled one-electron transfer reactions, and thirdly the reduction potentials are sensitive to the substituent pattern. Therefore, by "molecular engineering" the electron transfer behaviour of the furanoid compounds can be systematically tuned.

In the following a first attempt is undertaken to improve the understanding of the underlying structural constraints and of the kinetics of the individual electron transfer and chemical steps. 
The irreversibility of the electron transfer processes indicated by cyclic voltammetry of the monosubstituted arenes $1,4,8$ originates from a diffusion controlled reduction accompanied by a fast dimerization of the radical anion. For the phenyl compound 1a and related systems a detailed investigation of this dimerization reaction is already reported [24]. This suggests a strong localization of the negative charge and spin density on the side group which leads to chemical and consequently kinetic destabilization. The comparison of the meta and para substituted benzenes $2 \mathbf{a}, 3 \mathbf{a}$ and the 2.5-disubstituted heteroarenes $\mathbf{5 a}, \mathbf{6 a}$ points to a more efficient transmittance of substituent effects through the heterocyclic core unit, leading to a better stabilization of both the radical anion and the dianion of the furan and thiophene derivatives. From these results a charge distribution as indicated by $\mathbf{B}$ and $\mathbf{C}$ is derived (Formula 2). The radical ions of furans $\mathbf{5}$ and 7 and thiophenes 6 may therefore be incorporated into the group of stable distonic [25] radical ions which exhibit spatial separation of negative charge and spin density [26]. The standard reduction potentials of the reduction of furan $5 \mathbf{a}\left(E^{\circ}=-890 \mathrm{mV}\right)$ and thiophene $6 \mathbf{a}\left(E^{\circ}=-808 \mathrm{mV}\right)$ allude to the efficiency of sulfur to stabilize negative charge.

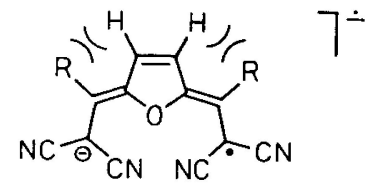

B

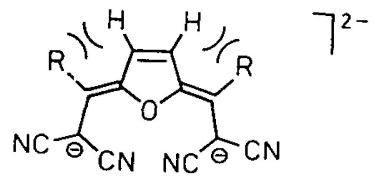

C

The extent of the stabilization of the radical anions by spatial separate localization of negative charge and spin density (structure B) also relates to their life-times which at least qualitatively can be obtained from the cyclovoltammograms. While the meta-compound $3 \mathbf{a}^{-}$- dimerizes rapidly (no oxidation peak for the radical anion, even at a scan rate of $5 \mathrm{~V} / \mathrm{s}$ ) the follow-up reaction in the case of $\mathbf{2 a}^{--}$is significantly slower (an oxidation peak can be observed at scan rates $>250 \mathrm{mV} / \mathrm{s}$ ). The radical anion $\mathbf{5 a}^{\circ-}$ appears to be stable under the prevailing conditions. The same is true for $\mathbf{6 a}^{\mathbf{a}^{-}}$. The pyrrol radical anion $\mathbf{9}^{--}$undergoes a subsequent reaction presumably under participation of the $\mathrm{N}-\mathrm{H}$-group.

The increase of acceptor strength by additional cyano groups facilitates reduction as expected. In case of the hexacyano substituted furan derivative $\mathbf{5 b}$ the half-wave potentials both of the radical anion formation and dianion formation are shifted to more positive values compared to the tetracyano compound $5 \mathbf{a}(685 \mathrm{mV}$, respectively $670 \mathrm{mV})$. The same applies to the thiophene derivatives $6 \mathbf{a}$ and $\mathbf{6 b}$ leading to slightly smaller potential differences $(623 \mathrm{mV}$ and $599 \mathrm{mV})$. The hexacyano compounds $\mathbf{5 b}$ and $\mathbf{6 b}$ exhibit 
Table 4. Standard reduction potentials $\left[E^{\circ}\right.$ in $\mathrm{mV}$ vs. FOC] for the reduction of tetra-, penta- and hexacyano compounds $5 \mathbf{a}-\mathbf{c} \mathbf{6 a - c}$ and TCNQ, and differences in the standard reduction potentials of radical ion and dianion formation.

\begin{tabular}{lllcl}
\hline$n^{\mathbf{a}}$ & compounds & $\begin{array}{l}E_{\mathbf{i}}^{\mathbf{o}} \\
(\mathrm{mV})\end{array}$ & $\begin{array}{l}E_{\mathrm{1}}^{\mathrm{o}} \\
(\mathrm{mV})\end{array}$ & $\begin{array}{l}E \Delta_{\mathbf{1}-\mathrm{n}}^{\mathbf{b}} \\
(\mathrm{mV})\end{array}$ \\
\hline 4 & $\mathbf{5 a}$ & -890 & -1240 & 350 \\
5 & $\mathbf{5 c}$ & -443 & -876 & 433 \\
6 & $\mathbf{5 b}$ & -205 & -570 & 365 \\
4 & $\mathbf{6 a}$ & -808 & -1114 & 306 \\
5 & $\mathbf{6 c}$ & -424 & -822 & 398 \\
6 & $\mathbf{6 b}$ & -185 & -515 & 330 \\
4 & TCNQ & -185 & -730 & 545 \\
\hline
\end{tabular}

${ }^{\text {a }}$ Number of cyano groups.

b $\Delta E_{\mathrm{I}-\mathrm{II}}^{\mathrm{o}}=E_{\mathrm{l}}^{\mathrm{o}}-E_{\mathrm{Il}}^{\mathrm{o}}$ (in $\mathrm{mV}$ ).

three consecutive one-electron reduction waves, inclusive the reversible formation of trianions $\left(5 \mathbf{b}^{2-} / \mathbf{5} \mathbf{b}^{3-},-1990 \mathrm{mV} ; \mathbf{6} \mathbf{b}^{2-} / \mathbf{6} \mathbf{b}^{3-},-2290 \mathrm{mV}\right)$. These observations are on the same line as the results reported on the reduction of meta- and para phenylene compounds $\mathbf{2 b}$ and $\mathbf{3 b}$ [21].

The dependency of the electrochemical reduction on the substituent pattern is demonstrated by the difference in the standard reduction potentials $\left(\Delta E_{\mathrm{I}-\text { II }}^{\circ}\right)$ (Table 4$)$.

A fifth nitrile group appears to specifically stabilize the radicals anions compared to the corresponding dianions (cases $5 \mathbf{c}$ and $\mathbf{6 c}$ ) leading to larger potential differences between radical anion and dianion formation. This again advocates the contribution of valence-bond structure $\mathbf{B}$ and the importance of distonic-type charge distribution.

The hexacyano derivatives $5 \mathbf{b}$ and $\mathbf{6 b}$ have nearly the same reduction potential for the radical anion formation $\mathrm{R} / \mathrm{R}^{\circ-}$ as $7,7,8,8$-tetracyanoquinodimethane (TCNQ) (Table 4). The reduction potential of the second wave $\left(\mathrm{R}^{\cdot-} / \mathrm{R}^{2-}\right)$ is anodically shifted in the heteroaryl compounds.

To highlight the effect of extended conjugation of the side chain on the electrochemical behaviour a summary of the redox potentials of compounds 5a and $7 \mathbf{a}-\mathbf{g}$ is given in Table 5. Although a quantitative relationship can not be given at this stage a qualitative assessement can be made by considering the potential differences $\Delta E_{\mathrm{I}-\mathrm{II}}^{\mathrm{o}} \cdot \Delta E_{\mathrm{I}-\mathrm{II}}^{\mathrm{o}}$ decreases from $350 \mathrm{mV}$ in $5 \mathrm{a}$ to $290 \mathrm{mV}$ in $7 \mathrm{e}, 160 \mathrm{mV}$ in $7 \mathrm{f}$ and $135 \mathrm{mV}$ in $7 \mathbf{a}$ and amounts to increasing negative numbers in the series $7 \mathbf{b}, 7 \mathrm{c}, 7 \mathrm{~g}$ and $7 \mathrm{~d}$. While in $5 \mathbf{a}, 7 \mathbf{a}$, $7 \mathbf{e}$, and $7 \mathbf{f}$ both reduction waves are definitely separated compounds, $7 \mathbf{b}-$ $\mathrm{d}$ and $7 \mathrm{~g}$ exhibit a single reduction-wave pertaining to a two-electron redox 
Table 5. Reduction potentials of the furanoid compounds $7 \mathbf{a}-\mathbf{g}$ and $5 \mathbf{a}$ for comparison (in $\mathrm{mV}$ vs. ferrocen).

\begin{tabular}{llrrr}
\hline & $n^{\mathbf{a}}$ & $E_{\mathrm{I}}^{\mathrm{o}}$ & $E_{\mathrm{II}}^{\mathbf{o}}$ & \multicolumn{1}{c}{$\Delta E^{\mathbf{o}}$} \\
\hline $\mathbf{5 a}$ & 4 & -890 & -1240 & 350 \\
$\mathbf{7 a}$ & 5 & -930 & -1065 & 135 \\
$\mathbf{7 b}$ & 6 & -1073 & -1050 & -23 \\
$\mathbf{7 c}$ & 6 & -995 & -965 & -30 \\
$\mathbf{7 d}$ & 8 & -1240 & -970 & -280 \\
$\mathbf{7 e}$ & 4 & -970 & -1260 & 290 \\
$\mathbf{7 f}$ & 4 & -1110 & -1270 & 160 \\
$\mathbf{7 g}$ & 6 & -1185 & -1132 & -53 \\
\hline
\end{tabular}

${ }^{a} n=$ number of double bonds between the acceptor groups.

process [27]. Polyene 7d has the most pronounced interchange of the redox potentials leading to $\Delta E_{\mathrm{I}-\mathrm{II}}^{\mathrm{o}}<-180 \mathrm{mV}$. Obviously, a clear correlation exists between the sign of $\Delta E_{\mathrm{I}-\mathrm{II}}^{\mathrm{o}}$ and the number of conjugated double bonds: Side groups with extended $\pi$-units result in an increase of the negative potential difference.

In the following three approaches are given to qualitatively discuss the molecular basis of the mutual interplay of kinetic and thermodynamic effects of the heterogeneous and homogeneous processes which lead to the findings described above.

(1): From structural considerations one might expect that the formation of the radical anion is accompanied by severe structural changes, especially if one assigns formula $\mathbf{B}$ (or its stereoisomers) to the radical anion. This should cause a significant decrease in the rates of the radical formations, particularly in case of the compounds with more extended side chains.

(2): By a specific stabilization of the dianions in the compounds with higher conjugated groups (e.g. $7 \mathbf{b}^{2-}-\mathbf{7 d}^{2-}$ and $7 \mathbf{g}^{2-}$ ) the fast homogeneous disproportionation of the radical anions could lead to a formally "two-electron" transfer process.

(3): It is interesting to note that a comparison of the curves, obtained from plots either of peak potential differences $\left(\Delta E_{\mathrm{p}}\right)$ or of peak current ratios versus the scan rates, with working curves published by Hinkelmann and Heinze [22] leads to the conclusion that the heterogeneous rate constants for the formation of the radical anions of $\mathbf{7 b - d}$ and $\mathbf{7 g}$ are larger than those for the formation of the corresponding dianions $k_{1}>k_{2}$ ). The absolute values however have not been determined yet. Further investigations to quantify these observations have to be made. Particularly since there appears to be a discrepancy to compounds as for example 
cyclooctatetraene (COT), dibenzocylooctatetraene (DBCOT) or substituted dibenzoheptafulvenes which also demonstrate two-electron waves on reduction, respectively oxidation [28]. In these cases $\left|E_{\mathrm{II}}^{\mathrm{o}}\right|$ appears to be larger than $\left|E_{I}^{o}\right|$. It is also found that the homogeneous rate constant $k_{1}$ (for COT reduction) is an order of magnitude smaller than $k_{2}$. Marcus's Theory [29] quantifies these results under the assumption of structural changes associated with the first electron-transfer step [30]. This could suggest that in our systems the second step may be accompanied by major structural reorganization [31].

Investigations to specify the mechanism of the electron transfer processes involved in the reduction of $5-\mathbf{7}$ are in progress.

The long-wave length absorptions of the neutral compounds $5 \mathbf{a}-\mathbf{c}$ and $\mathbf{6 a}-\mathbf{c}$ which have to be assigned to HOMO/LUMO transitions correlate at least on a qualitative level with the reduction potentials of the compounds [32]. This tendency however is not so pronounced in the polyenes $7 \mathbf{a}-\mathbf{g}$.

The spectra of the radical anions are strongly shifted towards higher wave-length, compared to the neutral compounds, and display a characteristic pattern with an intense absorption $(\lg \varepsilon=5)$ in the visible and two additional absorptions reaching into the NIR-region. As already found for the neutral compounds $5 \mathbf{a}-\mathbf{c}$ and $\mathbf{6 a}-\mathbf{c}$ there is a correlation relating a red-shift of the intense absorption band and an increasing positive potential for the $\mathrm{R}^{\cdot-} / \mathrm{R}^{2-}$-reduction. The intense absorption maxima of the dianions are in between those of the radical anions and the neutral compounds [33].

To summarize, by this study it is shown that, unlike to benzenoid compounds, acceptor substituted furans and thiophenes are found to be reversibly reduced to radical anions and dianions. It also turns out that by appropriate substitution the electron transfer properties can be systematically variied. This accounts both to the absolute value of the standardreduction-potential and to the mechanism of multi-electron-transfer. Cyclic voltammetry and spectroelectrochemistry turn out to be complementary techniques to contribute to these investigations.

\section{Outlook and applications}

The results given before recommend furans 5 and 7 and thiophenes 6 for applications in several areas, four of which will be briefly addressed in the following:

(a) Prospects as electron-transfer mediators: The usability should benefit from the reversibility of the redox-behaviour, the variability of the redox potentials and the availability of either one- or "two-electron" transfer compounds.

(b) Prospects as stable radical anion salts: The formation of solid-state charge-transfer complexe are under investigation. Refering to the work of 
Hirsch and Scalapino [34] who showed by Monte-Carlo simulation that theoretically two-electron-transfer reagents ("double valence fluctuating molecules") should have prospect in superconductor chemistry with a high transition-temperatur $\left(T_{\mathrm{c}}\right)$ it would be of interest to investigate the "oneelectron-transfer" and the "two-electron-transfer"-compounds alike. Linear extended anions further seem to increase the transition temperature in radical ion salts [35].

(c) Prospects as electrochemichromic molecular units: The electrochemical and spectroscopical properties contributing to electrochemichromism is already given in the tables. Scheme 2 compares the furanoid compound 5a and the thiophene 6a. In this respect it is worth to mention that compounds with absorption changes in the near infrared are of interest for optical storage, due to the utilisation of semiconductor lasers and fiber optic transmission in this range of the spectrum [36].

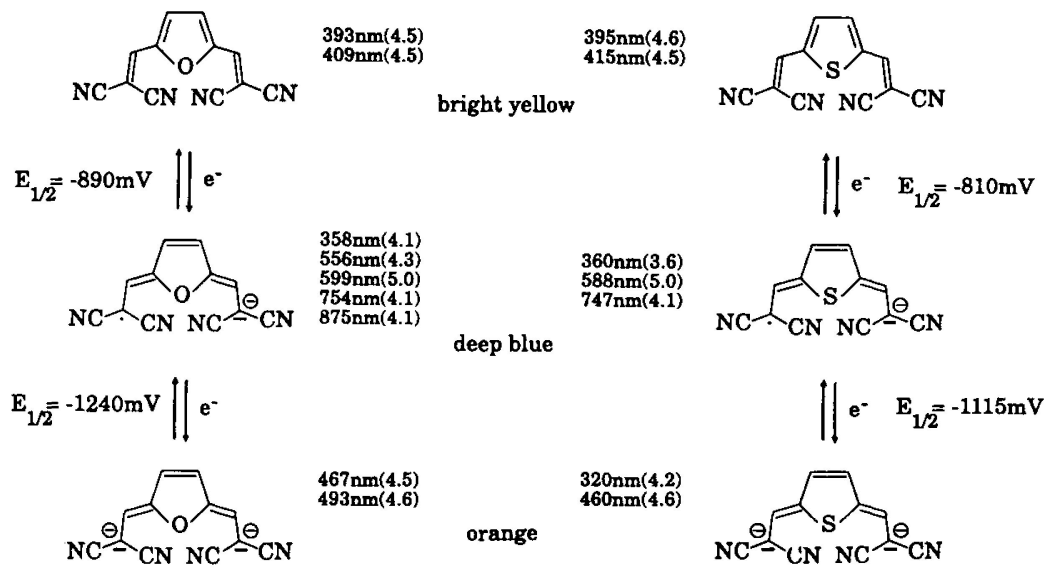

Scheme 2. Electrochemichromism of $5 \mathbf{a}$ and $\mathbf{6 a}$.

(d) Prospects as organic photoconductive materials: Some of the compounds have potential in the application as photoconductive materials. Two of the reasons are given in the following: J. E. Kuder et al. indicated that in mono-, di-and tri-cyanovinyl substituted aromatic compounds there exists a correlation in the generation of charge carriers and their reduction potential in solution [37]. The same should also apply to the compounds studied in this work. Furthermore, in photoconductive materials there appears to exist a direct correlation of the electrochemical stability of the acceptor components and the limitations of mobility due to trapping [8]. 


\section{Acknowledgement}

Financial support by Bundesminister für Forschung und Technologie, Volkswagen-Stiftung, and Fonds der Chemischen Industrie is gratefully acknowledged. We thank Südzucker AG Mannheim/Ochsenfurt for the sustained interest in the progress of this research.

\section{References}

1. For a preliminary report on aspects of this subjects, see: a) J. Daub, J. Salbeck, T. Knöchel, C. Fischer, H. Kunkely and K. M. Rapp, Angew. Chem. Int. Ed. Engl. 28 (1989) 1494; b) J. Daub, J. Salbeck, K. M. Rapp and H. Schiweck, 15 th International Carbohydrate Symposium, Abstract p D O28, Yokohama, Japan, 1990.

2. For review see: L. Eberson, Adv. Phys. Org. Chem. 18 (1982) 79.

3. For review see F. L. Charter (Ed.) Molecular Electronic Devices, Marcel Dekker Inc. New York 1982.

4. a) M. Chanon and M. L. Tobe, Angew. Chem. Int. Ed. Engl. 21 (1982) 1; b) J. M. Savéant, Acc. Chem. Res. 13 (1980) 323; c) S. Torii, Synthesis 1986, 873.

5. a) E. C. Ashby, Acc. Chem. Res. 21 (1988) 414; b) J. K. Kochi, Angew. Chem., Int. Ed. Engl. 27 (1988) 1227; c) A. Pross, Acc. Chem. Res. 18 (1985) 212.

6. a) E. E. Havinga and P. van Pelt, Mol. Cryst. Liq. Cryst. 52 (1979) 449; b) A. Donnadieu, Mater. Sci. Eng. B3 (1989) 185; c) M. Armand, Adv. Mat. 1990, 278; d) A. Yasuda and J. Seto, J. Electroanal. Chem. 247 (1988) 193; e) F. Pragst, Z. Chem. 21 (1981) 241.

7. a) J. H. Perlstein, Angew. Chem. Int. Ed. Engl. 16 (1977) 519; b) F. Wudl, Acc. Chem. Res. 17 (1984) 227; c) K. Nakasuji, Pure Appl. Chem. 62 (1990) 477.

8. R. O. Loutfy, Ah-Mee Hor, Cheng-Kuo Hsiao, G. Baranyi and P. Kazmaier, Pure Appl. Chem. 60 (1988) 1047.

9. a) A. Caneschi, G. Gatteschi, R. Sessoli and P. Rey, Acc. Chem. Res. 22 (1989) 392;

b) T. J. LePage and R. Breslow, J. Am. Chem. Soc. 109 (1987) 6412.

10. J. Heinze, Angew. Chem. Int. Ed. Engl. 23 (1984) 831.

11. a) T. Kuwana and W. R. Heineman, Acc. Chem. Res. 9 (1976) 241 ; b) W. R. Heineman, F. M. Hawkridge and H. N. Blount, Electroanal. Chem. 13 (1984) 1; c) Lit. [6e].

12. J. Daub, K. M. Rapp, P. Seitz and R. Wild, D. B. P. 3718917 (C1.C07D307/54, 15.12.88), Chem. Abstr. 110 (1989) P 212593k.

13. J. Daub, Nachr. Chem. Tech. Lab. 36 (1988) 896.

14. J. Daub, K. M. Rapp, J. Salbeck and U. Schöberl, in: Carbohydrates as Organic Raw Materials. Ed. F. W. Lichtenthaler, p. 323, VCH Publishers, Weinheim 1991.

15. J. F. Coetze (Ed.) Recommended Methods for Purification of Solvents and Tests for Impurities, Pergamon Press, Oxford 1983.

16. R. Carlier and J. Simonet, Bull. Soc. Chim. Fr. 1988, 831.

17. J. Salbeck, 1. Aurbach and J. Daub, Dechema Monographie, Band 112, S. 177. VCH Verlagsgesellschaft 1988.

18. R. L. Myers and I. Shain, Anal. Chem. 41 (1969) 980.

19. D. E. Richardson and H. Taube, Inorg. Chem. 20 (1981) 1278.

20. G. Manecke and D. Wöhrle, Makromol. Chem. 102 (1967) 1.

21. P. M. Allemand, P. Delhaes, Z. G. Soos, M. Nowak, K. Hinkelmann and F. Wudl, Synth. Met. 27 (1988) B243.

22. K. Hinkelmann and J. Heinze, Ber. Bunsenges. Phys. Chem. 91 (1987) 243.

23. Compare: S. Hünig and H. Berneth, Top. Curr. Chem. 92 (1980) 1 ; K. Deuchert and S. Hünig, Angew. Chem. 90 (1978) 927; Angew. Chem., Int. Ed. Engl. 17 (1978) 875. 
24. a) L. A. Avaca and J. H. P. Utley, J. Chem. Soc. Perkin Trans. I (1975), 971; b) A. J. Paine and R. O. Loutfy, Rev. Chem. Intermediates 5 (1984) 227: c) R. O. Loutfy, C. K. Hsiao, B. S. Ong and B. Keoshkerian, Can. J. Chem. 62 (1984) 1877; d) M. Sertel, A. Yildiz and H. Baumgärtel, Electrochim. Acta 31 (1986) 1625.

25. For definition, see: B. F. Yates, W. J. Bouma and L. Radom, J. Am. Chem. Soc. 106 (1984) 5805.

26. ESR-investigations to quantify these aspects as well as MO-calculations on this subject are in progress.

27. There is agreement that a "two-electron" transfer occurs in a stepwise two oneelectron transfer process, see: E. J. Calvo in "Chemical Kinetics", eds. C. H. Bamfort and R. G. Compton, Vol. 26: Electrode Kinetics, Principle and Methodology, Elsevier, Amsterdam 1986.

28. a) A. J. Fry, C. S. Hutchins and L. L. Chung, J. Am. Chem. Soc. 97 (1975) 591; b) H. Kojima, A. J. Bard, H. N. C. Wong and F. Sondheimer, J. Am. Chem. Soc. 98 (1976) 5560 ; c) W. Smith and A. J. Bard, J. Electroanal. Chem. 76 (1977) 19; b) R. Hahn, J. Salbeck and J. Daub, Chimia 42 (1988) 102.

29. R. A. Marcus, Annu. Rev. Phys. Chem. 15 (1964) 155.

30. On the interrelation of electron transfer and conformational changes, see: D. H. Evans and K. M. O'Connell, Electroanal. Chem. 14 (1986) 113.

31. An X-ray structure-analysis of furan 5a is available, indicating that in the solid state the neutral compound has a nearly planar structure, see: Lit. [14].

32. a) P. Zuman, Substituent Effects in Organic Polarography, Plenum, New York 1967; b) A. Streitwieser, jr., Molecular Orbital Theory for Organic Chemists, Wiley, New York 1961.

33. MO-calculations (AM-1 method) confirm these assignments. T. Clark, personal communication.

34. J. E. Hirsch and D. J. Scalapino, Phys. Rev. B32 (1985) 5639.

35. A. M. Kini, U. Geiser, H. H. Wang, K. D. Carlson, J. M. Williams, W. K. Kwok, K. G. Vandervoort, J. E. Thompson, D. L. Stupka, D. Jung and M.-H. Whangbo, Inorg. Chem. 29 (1990) 2555.

36. a) M. Emmelius, G. Pawlowski and H. W. Vollmann, Angew. Chem. Int. Ed. Engl. 28 (1989) 1445; b) G. P. Agarwal and N. K. Dutta, Long Wave length Semiconductor Lasers, Van Nostrand and Reinhold, New York 1986.

37. J. E. Kuder, W. W. Limburg, J. M. Pochan and D. Wychick, J. Chem. Soc. Perkin Trans. II 1977, 1643. 